\title{
Epidemiological Study of Brucellosis in Ardabil
}

\author{
Adham D, Abasi R, Abazari M, Ghorbani E, Ataey A and Moradi-Asl E*
}

Department of Public Health, School of Public Health, Ardabil University of Medical Sciences, Ardabil, Iran

*Corresponding author: Eslam Moradi-Asl, Department of Public Health, School of Public Health, Ardabil University of Medical Sciences, Ardabil, Iran, Tel: 00989050262483; Email: moradiasl83@yahoo.com

\section{Research Article \\ Volume 3 Issue 1}

Received Date: April 04, 2019

Published Date: April 30, 2019

DOI: $10.23880 /$ eij-16000122

\section{Abstract}

Brucellosis is a chronic and infectious zoonosis disease which is reported in many developing countries, including Iran. The aim of this study was to investigate the prevalence and incidence rate of brucellosis in the Ardabil County. In this descriptive study, all patients with brucellosis who were identified and treated were studied during the year 2013-2017. Individual information and some epidemiologic parameters of the patient were collected and analyzed by using SPSS 23 software. 372 cases in Ardabil county was identified and treated that $56.2 \%$ were mail and $43.8 \%$ female. $64 \%$ of patients located in rural and $36 \%$ in urban areas. The highest morbidity rate was observed in animal husbandry and farmer (32\%) and followed by housekeeping (20.4\%). In this study, the incidence of brucellosis was 2-33 /100,000 for over 5 years that increased from 2013 to 2017. According to the results of this study, the incidence of disease in the Ardebil County was moderate and in rural areas with husbandry and farmer, more was more than urban areas, therefore, it has to be planned in the field of education for the prevention of disease in rural areas

Keywords: Brucellosis; Epidemiology; Incidence; Ardebil; Iran

\section{Introduction}

Brucellosis, which is classified as an allergic and zoonotic disease, is caused by brucellosis gram negative bacteria [1]. In addition to the health problems, this disease causes economic problems, which in many countries, including Iran, due to economic growth and employment depend largely on agriculture and livestock, this disease is also considered as one of the economic growth concerns [2]. This systemic infection has a very diverse and non-specific clinical manifestation [3]. So that, apart from tuberculosis and syphilis, no disease is more diverse than brucellosis in terms of clinical manifestations [4]. In animals, it causes urinary tract infection and in humans usually causes fever, sweating, weakness, lethargy, and may also infect a person in organs such as the liver of the spleen and bones [5]. The routes of transmission of this disease to humans are classified in three categories: direct contact with blood, lymph and infected mucous membranes or damaged skin - through eating meat or dairy products by breathing aerosols [6]. The disease is of all ages, but its abundance is more common in the middle ages, so the workforce of the community is at risk. The abundance of disease in rural areas is higher [6]. Global reports have shown that around 500,000 new cases occur globally annually, and annual brucellosis in the Mediterranean and Middle Eastern regions is between 1 and 87 per 100,000 people, In Iran it is also known as an indigenous condition, and today it is between 108105 per hundred thousand variables [7]. Due to the many health problems that the disease causes and considering the fact that the northern regions And northwest including Ardebil province, it is necessary to determine the basis for the elaboration of strategies for fighting and controlling the disease by recognizing the epidemiological characteristics of the disease as well as the ways of transmission of the disease [8]. Methods: In 
this descriptive study, all patients with brucellosis who were identified and treated during the year 2012-2017 were studied. Individual information and some epidemiologic parameters of the patient were collected and categorized and analyzed by using SPSS 23 software.

\section{Material and Methods}

Study area: Ardabil province is one of 31 provinces of Iran located on the northwest of the country with a longitude of 38.2514 and latitude of 48.297 3. The population of province was 1270420 people in 2017 .

This province has 10 counties and has a cold region in the northwest of Plateau with an area of 17952.5 Sq.km. It is part of the triangular Plateau of Iran in the east of Azerbaijan Plateau, about $2 / 3$ of which has mountainous texture with high altitude and the rest is formed by the flat and low areas. The climate of Ardabil province is largely dependent on four factors of altitude, latitudes, water resources and Migratory Lows. Other factors such as vegetation, industrial and mining agricultural activities affect in small (Figure 1) [9-11].

\section{Data Analysis}

This descriptive cross-sectional study was performed on the individuals of all Brucellosis recorded

\section{Epidemiology International Journal}

in the Healthcare facility Ardabil County in 2013-2017. To collect this information, a researcher-made checklist that was approved by the experts was used. For analyze the data we used SPSS 23.

\section{Results}

During the study years (2012-2017), 372 new cases of brucellosis were reported from urban and rural areas of Ardabil city. The highest incidence (33 cases per 100,000 people) in the year 94 and was the lowest incidence ( 2 per 100,000 people), and the incidence rate declined from 94 to 95 and reached 19 per 100,000 people. For the age of 122 , under $25,166,25-50$, and 88 are 75-50, the rest are over 75 years old and have the highest age of 88 years and the lowest age of 1 year. Of the 372 patients studied (209 cases), $56.2 \%$ were male and (163), $43.8 \%$ were female, (136), 36\% were urban and (236), 64\% were rural, the highest number were occupied by livestock and farming (119), 32\% and then housekeeping (\% 78) 20.4\%. In terms of literacy rate (254 persons), 68\% were illiterate, and (93) $25 \%$ had diploma, (231 persons), 62\% were in contact with livestock and (141) 38\% ، (314 people) 84\% Dairy use history and (58\%) 16\% Non-dairy use (131) 36\% Livestock vaccination and (241) 64\% Non-vaccination، (136) 36\% Have a history of They had a brucellosis fever in the family.

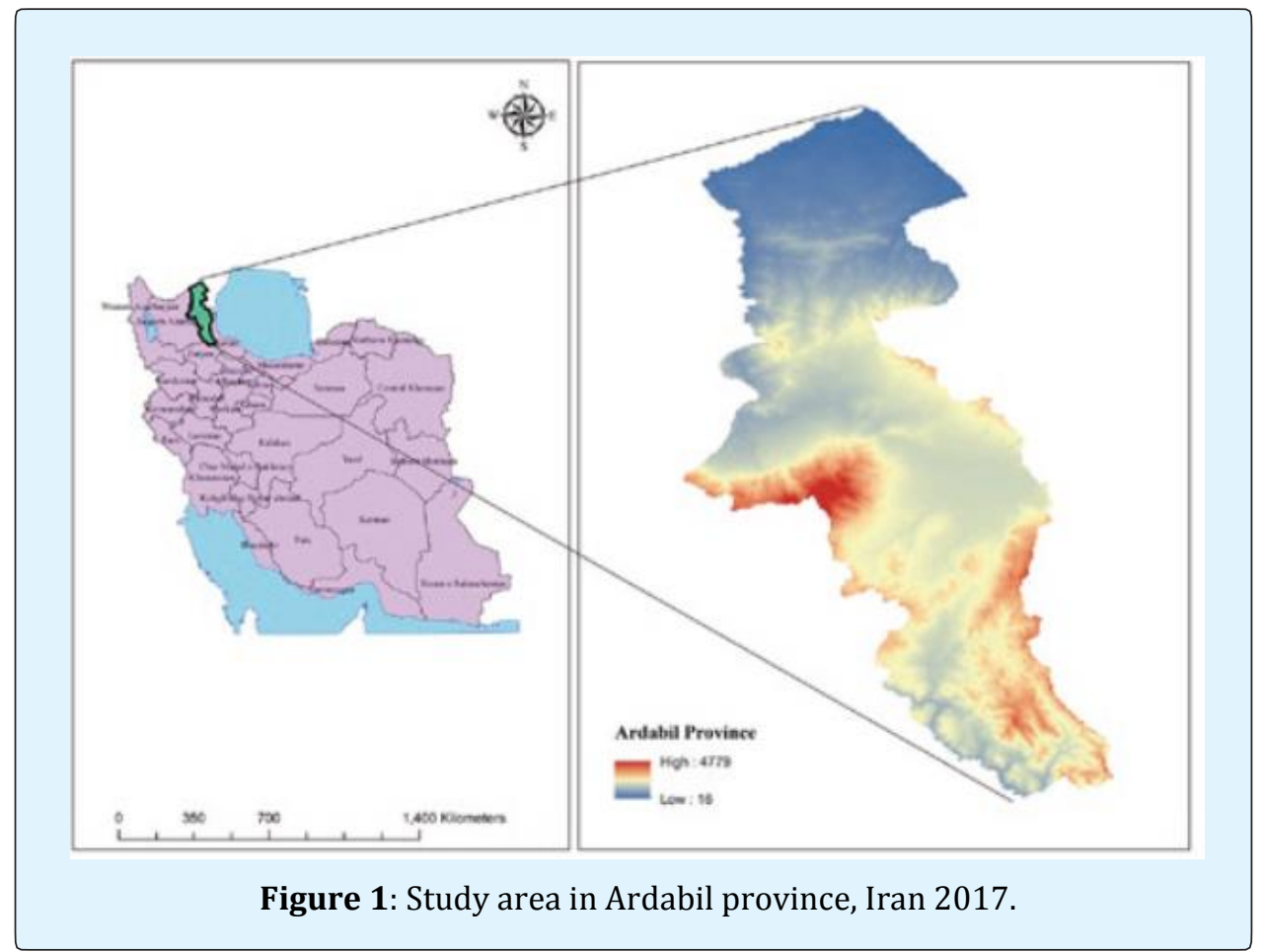

\section{Discussion}

This study was conducted to describe the epidemiology of brucellosis in Ardebil the research showed that the highest rates of brucellosis in 2016 in the county with 33 cases per 100,000 people were observed. Obviously, this amount is limited to the number of cases diagnosed and reported to the health center of the city, so it is likely that the actual incidence 
of disease in the city is more than this. A large number of cases of mumps will not be detected. It is estimated that even in advanced countries, only 10 to 4 percent of cases of brucellosis are diagnosed [9]. In general, it seems that in the world about 20-10 times less than the definitive cases [10] in Ardabil in the years 95-91 about 372 human cases of brucellosis has been reported.

According to a study conducted in Iran in 2003, the incidence of the disease was reported by 21 cases per 100,000 [11]. Zainali, et al. Also reported the incidence of illness in 2010 as 15.9 per 100,000 people [8]. Mallo in his study using spatial analysis showed that the incidence of brucellosis in the west, northwest and northeast of the country was significantly higher than in other parts of the country [12]. Although the prevalence of brucellos was $56.2 \%$ higher than that of females $(43.8 \%)$, it does not seem to be significant. This prevalence in males can be due to several reasons, including a job, this superiority in Ibrahim Pour's studies [13], Kasiri [14], and in a study done by the Republic of Macedonia [15], another study in Isfahan showed that most cases were in the age group of 15-20 years old [16]. Ebrahimpur also mentioned in his study that $67.8 \%$ of cases occur at the age of $10-50$ years [13]. Also Kasiri et al. In their study, in the city of Azna, the age group of 15-24 years had mentioned the most involved age group [14]. Based on the results of this study, it can be said that the disease at young and middle ages is more than these results are consistent with the findings of other studies $[13,14]$. In terms of occupation, the most cases of disease were in livestock breeders and farmers were $32 \%$ and housewives were $20.4 \%$. In rural areas of Ardebil, an important part of livestock affairs, including grazing and livestock feeding, milking and supplying different dairy products, Housewives are therefore the most affected by rural women. According to Qazvin University of Medical Sciences, Semnan, Kurdistan, Birjand and Lorestan, housewives were the most affected group [17]. Among the factors that increased the risk of disease, the use of non-pasteurized dairy products had the greatest role in the transmission of disease (84\%) and also in the study of Ebrahimpur the most common pathway was the transmission of non-pasteurized cheese with $45.1 \%$ [13]. Zeinali [6] and Kasiri also mentioned their raw milk as the most important route of disease in their study[15] which is consistent with the findings of other studies in Lebanon, Turkey, Macedonia and Iran $[12,15,17]$. This is not the case when a study was conducted in Kurdistan [17].

Regarding the fact that spring and summer usually have the largest lactation season, most cases are seen in these seasons. Considering the prevalence of agricultural and horticultural activities as the main occupation of villagers, it is necessary that a wider and more comprehensive coverage of vaccination, care for the disease, Monitoring livestock slaughter, monitoring livestock imports, adequate supervision of the production and distribution of dairy products, or training on how to properly produce healthy dairy products, and informing and educating people at all levels and sectors, especially in high-risk areas City to be done. It is also necessary to give villagers the opportunity to control risk factors. In highly infected areas, colleagues need to be more sensitive and aware of rural centers and hygiene homes than brucellosis.

\section{Conclusion}

According to the results of this study, the incidence of disease in the Ardebil County was moderate and in rural areas with husbandry and farmer, more was more than urban areas, therefore, it has to be planned in the field of education for the prevention of disease in rural areas.

\section{References}

1. Deqiu S, Donglou X, Jiming Y (2002) Epidemiology and control of brucellosis in China. Vet Microbiol 90(1-4): 165-182.

2. Azizi F, Janghorbani M, Hatami H (2000) Epidemiology and control of common disorders in Iran. Iran Publication, Tehran, pp: 32.

3. Akhvlediani T, Clark DV, Chubabria G, Hepburn MJ, Zenaishvili $O$ (2010) The changing pattern of human brucellosis clinical manifestations, epidemiology, and treatment outcomes over three decades in Georgia. BMC Infect Dis 10: 346.

4. Zadeh Y (2001) Epidemiological clinical diagnostic and therapeutic survey in 505 cases with Brucellosis. Tehran Univ Med J 59(4): 34-46.

5. Tabatabaei SM, Zahraei M, Ahmadnai H, Ghotbi M, Rahimi F (2007) Principles of disease prevention and Surveillance. Disease management center, pp: 173.

6. Salari M, Khalili M, Hassanpour G (2003) Selected epidemiological features of human brucellosis in Yazd, Islamic Republic of Iran: 1993-1998. East Mediterr Health J 9(5-6): 1054-1060.

7. Zeynali M, Shirzadi M (2007) Effective Factors in the control and prevention of brucellosis in the past two decades. $2^{\text {nd }}$ National Iranian Congress ON Brucellosis- Shahid Beheshti University of Medical Sciences, pp: 106-108.

8. Rezaee $\mathrm{F}$ incidence epidemiological characteristics of brucellosis in Qom province during the years 2011-2015, the journal of infectious diseases and 


\section{Epidemiology International Journal}

tropical infectious disease specialists, Association affiliates and twentieth year, tropical, 70: 25-31.

9. Moradi-Asl E, Hanafi-Bojd AA, Rassi Y, Vatandoost H, Mohebali M, et al. (2017) Situational analysis of visceral leishmaniasis in the most important endemic area of the disease in Iran. J Arthropod Borne Dis 11(4): 482-496.

10. Moradi-Asl E, Rassi Y, Adham D, Hanafi-Bojd AA, Saghafipour A, et al. (2018) Spatial distribution of sand flies (Diptera: Psychodidae; Larroussius group), the vectors of visceral leishmaniasis in Northwest of Iran. Asian Pacific Journal of Tropical Biomedicine 8(9): 425.

11. Moradiasl E, Adham A, Solimanzadeh $H$, Saghafipour A, Eghbal H (2019) The Impact of Climatic Factors on Spatial Distribution of Scorpion Stings in Ardabil Province, North-West of Iran; 2012 - 2017. Shiraz E-Med J, Shiraz E-Med J 20(2): e69333.

12. Kamal S, Hashemi SS, Nasaji M, Moshiri E, Shahriyari R, et al. (2009) Frequency of reported cases of brucellosis toprovince health center from public and private sectors in Semnan 2006-2007. Koomesh Journal of Semnan University of Medical Sciences 10(2): 125-130.

13. Zoonoses Office (2012) National Guideline for Brucellosis control, Iranian Ministry of Health and Medical Education, Health Deputy Center for Diseases Control, pp: 1-8.
14. Zoghi A (2007) Theoretical Overview on human brucellosis. $2^{\text {nd }}$ National Iranian Congress ON Brucellosis, Shahid Beheshti University of Medical Sciences, pp: 47-74.

15. Mollalo A, Alimohammadi A, Khoshabi M (2014) Spatial and spatio-temporal analysis of human brucellosis in Iran. Trans $\mathrm{R}$ Soc Trop Med Hyg 108(11): 721-728.

16. Ebrahimpour S, Youssefi MR, Karimi N, Kaighobadi M, Tabaripour R (2012) The prevalence of human Brucellosis in Mazandaran province, Iran. Afr J Microbiol Res 6(19): 4090-4094.

17. Kasiri H, Amani H, Lotfi M (2013) Epidemiological, laboratory, diagnostic and public health aspects of human brucellosis in western Iran. Asian Pac J Trop Biomed 3(8): 589-594.

18. Donev D, Karadzovski, Kasapinov B, lazarevik V (2010) Epidemiological and public health aspects of brucellosis in the Republic of Macedonia. Prilozi 31(1): 33-54.

19. Dastjerdi MZ, Nobari RF, Ramazanpour J (2012) Epidemiological features of human brucellosis in central Iran, 2006-2011. Public Health 126(12): 1058-1062.

20. Moniri R, Dastegoli K (1997) Seroepidemiology of human Brucellosis in Kashan, 1996. KAUMS Journal (FEYZ) 1(1): 35-40. 